\title{
Patient's Perception towards Quality of Nursing Care in Inpatient Department at Public Hospitals of Benishangul Gumuz Regional State, North West Ethiopia
}

\author{
Sani Yenuss Kewi ${ }^{1}$, Abebe Abera Tesema ${ }^{1}$ and Bayisa Bereka Negussie $2^{2^{*}}$ \\ Department of Adult Health Nursing, Jimma University, Jimma, Oromia, Ethiopia \\ Department of Paediatrics and Child Health Nursing, Jimma University, Jimma, Oromia, Ethiopia
}

"Corresponding author: Bayisa Bereka Negussie, Department of Paediatrics and Child Health Nursing, Jimma University, Jimma, Oromia, Ethiopia, Tel: +251 47111 1458; E-mail: baayyisaab@gmail.com

Received date: July 24, 2018; Accepted date: Oct 22, 2018; Published date: Oct 29, 2018

Copyright: (c) 2018 Negussie BB. This is an open-access article distributed under the terms of the Creative Commons Attribution License, which permits unrestricted use, distribution, and reproduction in any medium, provided the original author and source are credited.

\section{Abstract}

Background: Quality nursing care service delivery is critical undertaking for optimal patient outcomes. Patient's perception of quality nursing care is the patient's feeling or view of the nursing care they received from nursing staff during hospital stay. Using patient's perception as proxy in measuring quality of nursing care is highly recommended.

Objective: The aim of this study is to assess patients' perception towards the quality of nursing care in inpatient department at public hospitals of Benishangul Gumuz regional state.

Methods: Institution based cross-sectional study design was employed from March 15 to April 30/2018. Stratified random sampling technique was used to select 421 eligible study participants. Interviewer administered structured questionnaire was employed to collect data. Data was entered to epidata version 3.1 and exported to SPSS version 23. Descriptive statistics was computed and binary logistic regression analysis was used to identify candidate variable. Then, variables found to have value of less than 0.25 was entered into multivariable logistic regression analysis. Finally, the p-values of $<0.05$ was considered statistically significant. Graph, table and chart were used for presenting results.

Results: The overall good perception was found to be $49.3 \%$. There was a statistically significant association between patients' level of education, length of hospital stay, companion possession status and type of room admission $(p<0.05)$. But, there was no statistically significant association between gender, age and previous hospitalization experiences with overall patient perception.

Conclusion and Recommendations: Authors conclude that the patients enrolled in the study perceived nursing care services in negative way, so their perception status with the care they received was found to be at a lower level. This requires imperative attention by responsible bodies to enhance patient perception. Further study is needed to understand the overall patients feeling using qualitative study and also the care providers' perceptions should be examined.

Keywords Nursing care; Quality; Inpatient department; Patient perception

\section{Introduction}

There is growing evidence that perceived quality is the single most important variable influencing consumers to purchase products or services. Quality Nursing Care (QNC) is extremely important for health care organizations [1]. QNC is defined as a process that sought to attain the highest degree of excellence in the delivery of patient care [2]. In this study, patient's perception of quality nursing care is defined as the patient's feeling or view of the nursing care they received from nursing staff during hospital stay and is acknowledged as an outcome indicator of the quality of nursing care [3]. Quality nursing care remains an important role for patient because nurses are involved in almost every aspect of client's care in hospital. Nurses also interact with patients more often than any other health care personnel in a hospital [4].

Patient perception is an important indicator which gives an idea about the quality of nursing care services. It also provides feedback to determine the quality and evaluation of nursing care [5]. Therefore, patients should be allowed to define their own priorities and evaluate their care accordingly, rather than having those criteria selected by professionals [6].

Health care professionals and patients view quality nursing care from different perspectives. Health care professionals view competent nursing care as quality nursing care [7]. Patients describe quality nursing care in terms of interpersonal care, efficiency; competency, comfort, personalized information, physical environment, and general instructions [8]. 
Mostly, quality of nursing care has been measured against expectations of health professionals and standards rather than being grounded in the perspectives of patients. Using patient's perception as proxy in measuring quality of nursing care is highly recommended, though, ignored in most research and organizational endeavour of low income countries thus far [9].

To ensure service improvement initiatives at appropriative levels in hospital is a prerequisite to understand factors which influence patients' perception about the received care. The measurement of patients' perception with quality nursing care is important to determine and meet patients' need in terms of nursing care and to evaluate quality of nursing care provided [10].

Sustaining the quality of hospital care and how to improve it has emerged to be a global challenge. This has resulted in various measures being developed to measure quality and no single method can be said to be the best. There is need to find out what constitutes quality care especially from the patient's perspective, together with views from healthcare managers and other groups [11].

The experience possessed by patients can offer alternatives of improving nursing care quality service that may not be observed from other perspectives, for instance, the way of treatment, process or interaction. Despite having various methods of quality measurement, the challenges always persist and there is a belief that measuring and acting on issues of quality raised by patients can provide solution to the problems [12].

Although the significance of measuring patient satisfaction with nursing care cannot be emphasized enough, currently the concern of patients' satisfaction with nursing care has attracted the attention of researchers across the globe. This is because of knowledge gained from patient satisfaction surveys can set a direction for quality improvement [13].

Currently the nursing profession has often use patient's outcome as a measure to assess the health care delivery system. It assists in the evaluation of nursing care practice quality and it also helps in bringing better improvements in the established nursing service [14]. Nurses are in a unique position to promote and influence effective relationships with the client. Because the nurses spent much time with the patients than any other health care workers [15].

The study showed that the most important factor affecting patient's perception in terms of hospital care is nursing service. Patient satisfaction study revealed that nursing care is the major determinant of the patient's satisfaction. Care that has been assessed to be high quality based on the economic, clinical or other providers-related criteria are not ideal, if the patient feels dissatisfied [16]. Patient satisfaction research result in Iran showed that dissatisfaction of nursing care service leads the patient to low utilization of nursing care service and developing negative attitude about the health care system. As a result, dissatisfied patients will not come back to hospital. Therefore, patients' satisfactions are not simply measure of quality; it is the goal of health delivery [17].

A study on patients' perception of quality nursing care stated that nurses' affective activities are more important for the quality nursing care than their technical skill. From this study, patients placed most emphasis on the nursing care that recognized them as a unique individual with their need to share feelings, to be accepted as a family member and to have someone listen to them [18].
Despite the fact that a study conducted in Jordan hospitals revealed that the perceived quality of nursing care is relatively low, patients were found less satisfied with both coordination and interpersonal aspect of the care provided. In this study, the author concluded that Jordanian healthcare organizations have performed below the average in providing quality care which considered significant to hospital administrators and directors of nursing [19].

A study undergone in Nigeria found that dignity was not completely maintained according to the standards expected by the patients. Nurses' attitude towards patients had great influence on patients' perception of nursing care. Quality of care is not only dependent on the care received, but also on the way the care delivered [20]. Patients' perception to health care system seems to have been largely ignored by health care administrators in developing countries [21].

The Ethiopian Federal Ministry of Health (FMOH) is struggling to provide quality health care service at every health institution through different strategies [22]. Although the needs of the clients are dynamic and are constantly influenced by demographical, social, environmental, cultural, economic and technological factors, patient satisfaction is not sufficient enough. Therefore, the health care system needs constantly determining the needs of the clients through patients' satisfaction surveys to go through a continuous change that is in accordance with the priority needs of the client and ensure the quality of nursing care services [23].

Research done in Axum has shown that the overall rating of nursing care quality was $65 \%$. The aspect of care which scored least were patient observation, pressure ulcer prevention and amount of information nurses give about their condition [24]. So, to improve the health care system the use of patients' perception of care is very important and also nurses should have a clear understanding of patient's need in order to plan individualized nursing care.

In addition, a study conducted in Mekelle Ethiopia showed that the overall patients' perception was found to be $49.7 \%$. In this study, regarding the nurses' characteristics, the nursing care related activities, and the information providing to the patient perceived was found to be $45.5 \%, 40.4 \%$, and $38.8 \%$ as poor respectively. The result indicated the need for professional accountability and responsibility to provide optimal standard nursing care [25].

The study undergone in Dessie referral hospital on adult patients' satisfaction revealed that the overall patients' satisfaction was $52.5 \%$. This study indicated the rate of patient satisfaction with the nursing care was low. The study further revealed that the type and amount of information nurses gave to the patient was the least scores [15].

In general, a very important aspect on which the patient satisfaction depends is on the nursing care, because nurses are involved almost in every aspect of client's care. A nurse who was perceived quality nursing care service had showed kindness, a good attitude and professional manner, thrust and honesty as well as clinical competence. To understand the patient satisfaction, Patient's perception towards nursing care must first be understood. Therefore, the purpose of this study was to assess patients' perception regarding the quality of nursing care and its contributing factors (Figure 1).

\section{Conceptual Framework}

Many studies in different parts of the world reviewed that patients' perception of quality nursing care is affected by different factors. For this study according to the literature review the main factors identified 
Citation: Kewi SY, Tesema AA, Negussie BB (2018) Patient's Perception towards Quality of Nursing Care in Inpatient Department at Public Hospitals of Benishangul Gumuz Regional State, North West Ethiopia. J Nurs Care 7: 467. doi:10.4172/2167-1168.1000467

Page 3 of 10

are socio-demographic status of the patient, patient related factors, hospital related factors.

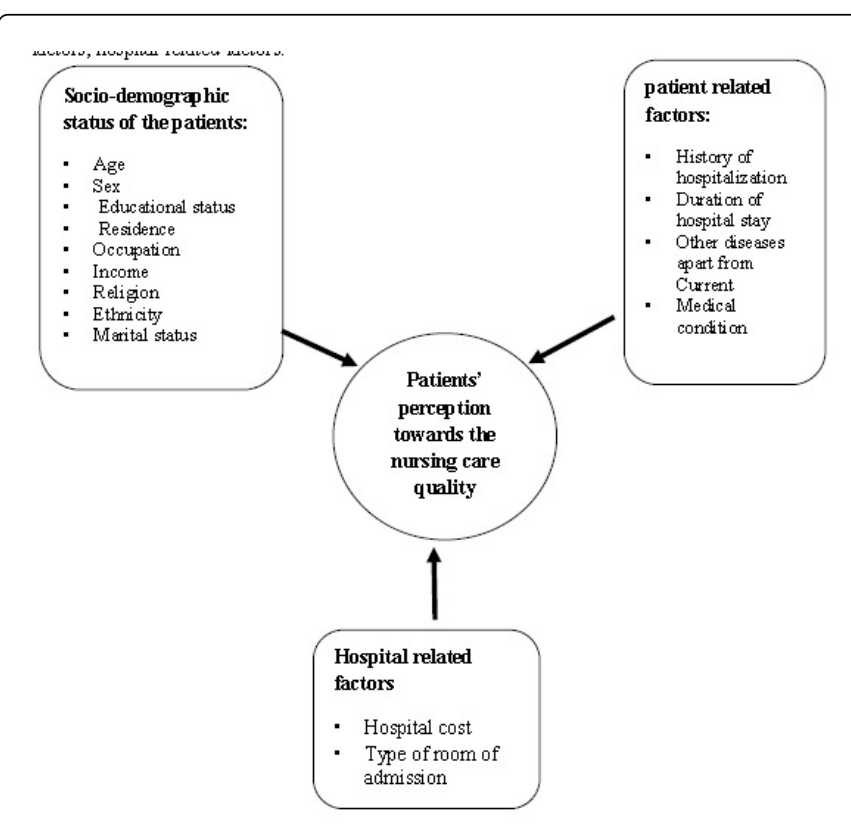

Figure 1: Conceptual frame work adapted from Gupta BS on patient's perception towards quality nursing care [7].

\section{Methods and Materials}

\section{Study area and period}

Institution based cross-sectional study design was conducted in public hospitals of Benishangul Gumuz Regional State, North West Ethiopia, from March 15/2018 to April 30/2018. Benishangul Gumuz Regional State is one of the nine regional states of the federal democratic republic of Ethiopia and $675 \mathrm{~km}$ far from Addis Ababa to the West. The region is administratively composed of 3 Zones and 20 Woredas. The population size of the region was estimated to be $1,000,000$ and the proportion of male and female was $50.7 \%$ and $49.3 \%$ respectively. Two general hospitals, 33 health centres and 378 health posts make the regional health care service coverage $87 \%$. Pawe general hospital was one of the public hospitals in the region. The hospital provides over 15 different services with 150 beds and 310 employees. The nurses give care for around 340 inpatients per month within four wards. Assosa general hospital was the second public hospital in the region. The hospital provides over 15 different services with 108 beds and 298 employees. The nurses give care for around 300 inpatients per month within four wards. All adult patients who were admitted to inpatient wards at public hospitals of Benishangul Gumuze Regional State were the source of population and all adult patients who were admitted to the Medical, Surgical, Gynaecology and Obstetrics wards in Assosa and Pawe general hospitals and eligible were the study population.

\section{Inclusion and exclusion criteria}

Patients whose age $\geq 18$ years and hospitalized patients who stayed in the ward at least for 3 days were included whereas patients who cannot respond/disoriented/altered mental status were excluded from the study.

\section{Sample size and sampling procedure}

The sample size for this particular study was calculated using a single population proportion formula considering the following assumptions:

The sample size was determined with $5 \%$ absolute precision and 95\% confidence interval. Proportion of patients' perception with the nursing care $(\mathrm{p}=50.3 \%)$ [25] was considered. Based on this assumption, the actual sample size for the study was as follows.

$$
\begin{aligned}
& \mathrm{n}=(\mathrm{Za} / 2)^{2} \mathrm{P}(1-\mathrm{P}) \mathrm{d}^{2} \\
& \text { Where } \mathrm{n}=\text { Sample size }
\end{aligned}
$$

$\mathrm{Z}=$ Value corresponding to a $95 \%$ level of significance $=1.96$

$\mathrm{p}=($ Proportion of patients' perception with the nursing care $50.3 \%)$

$\mathrm{q}=(1-\mathrm{p})=(1-0.5)=0.5$

$\mathrm{d}=$ Margin of error, assumed to be $5 \%$

Therefore, based on using the above single population proportion formula the sample size calculated as:

$$
\begin{aligned}
& \mathrm{n}=(1.96)^{2} 0.53(1-0.53)(0.05)^{2} \\
& \mathrm{n}=383
\end{aligned}
$$

For possible non-response rate, the final sample size was increased by $10 \%$ to 421 admitted patients. Stratified random sampling technique was applied and the total sample size $(n=421)$ was allocated proportionally for both hospitals based on the total number of patient flow in the hospitals. First, the number of patients to be taken from each ward was determined based on the number of patient flow they had. Then, through using a systematic random sampling technique, every $\mathrm{K}^{\text {th }}$ patient were included where $\mathrm{k}=2$ for both Hospitals that obtained total patient divided by the sample allocated for each hospital. The first patients were selected by lottery method from their order of registration and then every other patient who had received care was selected and those on the list will approached consecutively.

Data was collected through face to face interview using modified patients' perception of quality nursing Care which developed by Senarath and colleagues in Sri Lanka in 2011 by contextualizing local context and translating to local language. Patients' perception of nursing care was measured using the Likert scale of 5 points ( $1=$ Strongly disagree, $2=$ Disagree, $3=$ Neutral, $4=$ Agree and $5=$ Strongly agree) and Participants were asked to rate their perception with various aspects of nursing care by selecting only one number that best describes. Four diploma nurses for data collection and two BSC nurses as supervisor were recruited.

\section{Operational definition and definition of terms}

- Patient's perception of quality nursing care: It is defined as patient's feeling or view about the nursing care they received in their hospital stay in terms of interpersonal care, comfort, efficiency, personalized information, physical environment, and competency of nurses.

- Other disease: Patients who reported having other disease apart from the main admission case. 
Citation: Kewi SY, Tesema AA, Negussie BB (2018) Patient's Perception towards Quality of Nursing Care in Inpatient Department at Public Hospitals of Benishangul Gumuz Regional State, North West Ethiopia. J Nurs Care 7: 467. doi:10.4172/2167-1168.1000467

Page 4 of 10

- Acute condition: Patients who reported that experiencing of the admission case for less than 30 days.

- Chronic condition: Patients who reported that experiencing of the admission case for 30 days and above.

- Good perception: If the summed score of response of 26 perception questions is more than the median score, the patient was categorized as having good perception.

- Poor perception: If the summed score of response of 26 perception questions less than or equal to the median score, the patient was categorized as having poor perception.

\section{Data quality assurance and analysis}

Pre-test was conducted on Chgni general hospital on 5\% sample size 2 weeks before actual data collection after which correction of concepts and statements were made. The reliability analysis was performed on the final instrument to assess the internal consistency as measured by alpha Coefficient which was 0.86 for the total scale. Training was provided for data collectors and supervisors on data collection procedures to ensure the quality of the field operation. The questionnaire was prepared in English language and translated to local language; Amharic by experts. Since the data collectors were not from the hospital workers, the patient can talk freely what he/she felt heart fully about the quality of care without fearing for his/her future cares which increases the quality of data. The researchers and supervisors were closely supervising the data collection process and every day the researcher and supervisors contact with the data collectors to solve problems and correct errors as early as possible. The collected data was checked for completeness, consistency and responses in each question was coded for simplicity of data entry. Then, data was entered to EPIdata version 3.1 and exported to Statistical Package for Social Sciences (SPSS) version 23. Descriptive statistical analyses were computed to see the frequency distribution and binary logistic regression was used to identify candidate variable for multiple logistic regression. The variables with $\mathrm{p}$-value of $<0.25$ were taken to multivariable logistic regression analysis to determine the significant association. Model fitness was checked by Hosmer and Lemshow test. A median score was used to summarize the patients' perception as good and poor. Those who scored above the median score was taken as good and below or equal to the median score as perceived poor. Finally, the $p$-value $<0.05$ were considered statistically significant. Graph, table and chart were used for presenting results in order to give a clear picture of magnitude and relationships of various study variables.

\section{Ethical considerations}

Prior to data collection, ethical clearance was obtained from Institutional review board of Jimma University, Institute of health. An official support letter was also obtained from Benishangul Gumuze Regional health bureau. Permission was obtained from ward incharges to access the participants and informed consent was obtained from the study participant to confirm willingness for participation after explaining the objective of the study. The participants had also the right to refuse or terminate their participation at any point of time. The information provided by each respondent was kept confidential through anonymous recording and coding of questionnaire.

\section{Results}

\section{Socio-demographic characteristics}

Out of 421 desired participants, 418 included in the study which yields $99.3 \%$ response rate. Two hundred forty-seven (59.1\%) were females. More than half, 236 (56.5\%) of study participants were in age range of $18-30$ years with mean age of $34.88 \pm(S D=13.29)$ years. Nearly half of the respondents $(46.9 \%)$ were orthodox in religion and Amhara and Gumuz Ethnic group accounts 133 (31.8)\%, 81 (19.4\%) respectively. About one third $(34.7 \%)$ of the participants were unable to read and write whereas $109(26.1 \%)$ of the participants were farmer and 219 (52.4\%) were living in rural areas. On the other hand, 216 (51.7\%) of them earn 500-1000 ETB a month with their mean monthly income being 880.4 Ethiopian Birr (SD \pm 751.8 ) (Table 1, Figures 2 and 3).

\begin{tabular}{|l|l|l|l|}
\hline Variables & Category & Frequency & Percentage (\%) \\
\hline \multirow{4}{*}{ Sex } & Male & 171 & 40.9 \\
\cline { 2 - 4 } & Female & 247 & 59.1 \\
\hline \multirow{5}{*}{ Marital status } & $18-30$ & 236 & 56.5 \\
\cline { 2 - 4 } & $31-40$ & 99 & 23.7 \\
\cline { 2 - 4 } & $41-50$ & 65 & 15.6 \\
\cline { 2 - 4 } & 51 and above & 18 & 4.3 \\
\hline \multirow{5}{*}{ Religion } & Married & 304 & 72.7 \\
\cline { 2 - 4 } & Single & 92 & 22 \\
\cline { 2 - 4 } & Divorced & 9 & 2.2 \\
\cline { 2 - 4 } & Widowed & 13 & 3.1 \\
\hline & Orthodox & 196 & 46.9 \\
\cline { 2 - 4 } & Muslim & 163 & 39 \\
\hline
\end{tabular}


Citation: Kewi SY, Tesema AA, Negussie BB (2018) Patient's Perception towards Quality of Nursing Care in Inpatient Department at Public Hospitals of Benishangul Gumuz Regional State, North West Ethiopia. J Nurs Care 7: 467. doi:10.4172/2167-1168.1000467

Page 5 of 10

\begin{tabular}{|c|c|c|c|}
\hline & Catholic & 21 & 5 \\
\hline & Protestant & 38 & 9.1 \\
\hline \multirow[t]{7}{*}{ Ethnicity } & Amhara & 133 & 31.8 \\
\hline & Oromo & 66 & 15.8 \\
\hline & Shinasha & 46 & 11 \\
\hline & Berta & 64 & 15.3 \\
\hline & Gumuz & 81 & 19.4 \\
\hline & Agew & 10 & 2.4 \\
\hline & Others & 18 & 4.3 \\
\hline \multirow[t]{5}{*}{ Educational status } & unable to read and write & 145 & 34.7 \\
\hline & Able to read and write & 51 & 12.2 \\
\hline & Primary school & 101 & 24.2 \\
\hline & Secondary School & 77 & 18.4 \\
\hline & College and above & 44 & 10.5 \\
\hline \multirow[t]{6}{*}{ Occupation } & Government employee & 47 & 11.2 \\
\hline & Merchant & 40 & 9.6 \\
\hline & Farmer & 109 & 26.1 \\
\hline & House wife & 68 & 16.3 \\
\hline & Private employee & 131 & 31.3 \\
\hline & Other & 23 & 5.5 \\
\hline \multirow[t]{2}{*}{ Place of residence } & Rural & 219 & 52.4 \\
\hline & Urban & 199 & 47.6 \\
\hline \multirow[t]{5}{*}{ Income classification } & $<500$ & 106 & 25.4 \\
\hline & $500-1000$ & 216 & 51.7 \\
\hline & $1001-1500$ & 50 & 12 \\
\hline & $1501-2000$ & 15 & 3.6 \\
\hline & $>2000$ & 31 & 7.4 \\
\hline
\end{tabular}

Table 1: Socio-demographic characteristics of patients' in public hospitals of Benishangul Gumuze ( $\mathrm{n}=418$ ), Note: Others (Ethnicity): Kenbata, Tigre, Mao, Komo, Others (Occupation): student, prisoners.

\section{Patient and admission related characteristics}

Among participants, $386(92.3 \%)$ were admitted in the common room. Concerning service, 339 (81.1\%) of participants had paid for the service they received. A considerable number of patients, $340(81.3 \%)$ were admitted for acute illness. Moreover, 341 (81.6\%) of patient did not have other diseases apart from current health problem. Majority of respondents, 389 (93.1\%) had family support/Companion Possession in their hospital stay and concerning the hospital cost, more than half (52.3\%) of respondents perceived it as medium followed by 158 (46.5\%) of respondents perceived as high cost. Three hundred seventyone $(88.8 \%)$ of the participants stayed in the study hospitals for $\leq 7$ nights with the mean length of stays (nights) of $5.2(\mathrm{SD} \pm 2.5)$ (Table 2).

\section{Patients' perception about the quality of nursing care}

The results of this study revealed that, 206 (49.3\%) of the study participants had good perception about the overall nursing care quality they received. Nearly half of respondents, 202 (48.3\%) had good perception regarding on interpersonal nursing care related dimension. Among this, nurses friendly communicate with the patients 297 (71.1\%), nurses maintain the individual respect 265 (63.4\%), nurses show willingness when asked for help $260(60.2 \%)$ were the three aspects of nursing care services which had good perception with the 
Citation: Kewi SY, Tesema AA, Negussie BB (2018) Patient's Perception towards Quality of Nursing Care in Inpatient Department at Public Hospitals of Benishangul Gumuz Regional State, North West Ethiopia. J Nurs Care 7: 467. doi:10.4172/2167-1168.1000467

Page 6 of 10

highest proportion of the study participants. On the contrary, nurses did most of the things by asking them, nurses involve the patients and their family in patient care and nurses immediately took care of their requests were 208 (49.8\%), 134 (32.1\%) and 100 (23.9\%) respectively.

On the second dimension of nursing care, 164 (39.2\%), 186 (44.5\%), $306(73.2 \%)$ and $168(40.2 \%)$ of respondents had good perception on nurses gave treatment/medication without any delay, nurses maintained records efficiently, enough number of nurses were available for their care and nurses maintain good coordination with other staff respectively.

Regarding on patient comfort, 266 (63.6\%), 75 (17.9\%) and 75 (17.9\%) of them had good perception on efforts taken for ensuring privacy during examination, peaceful environment in the ward and cleanliness of the bed respectively. Related to the information given by the nurse out of the total participants, 107 (25.6\%), 111 (26.6\%), and $162(38.8 \%)$ of them had good perception with the amount of information provided on facilities available when first came to the ward, the amount of information provided regarding the illness and the amount of information provided regarding on investigations respectively.

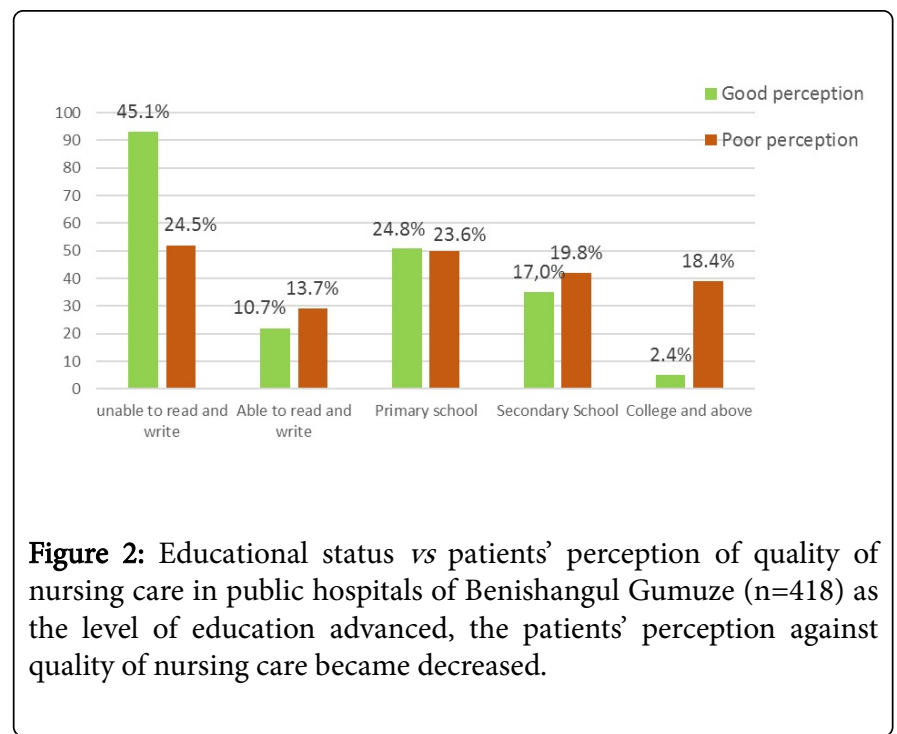

\begin{tabular}{|c|c|c|c|}
\hline Variables & Category & Frequency & Percentage (\%) \\
\hline \multirow[t]{3}{*}{ Admission ward } & Medical & 153 & 36.6 \\
\hline & Surgical & 128 & 30.6 \\
\hline & Gyn/obs & 137 & 32.8 \\
\hline \multirow[t]{2}{*}{ Number of days stayed in hospital } & $\leq 7$ & 371 & 88.8 \\
\hline & $\geq 8$ & 47 & 11.2 \\
\hline \multirow[t]{2}{*}{ Service type } & Free & 79 & 18.9 \\
\hline & Payment & 339 & 81.1 \\
\hline \multirow[t]{2}{*}{ History of previous admission } & Yes & 154 & 36.8 \\
\hline & No & 264 & 63.2 \\
\hline \multirow[t]{2}{*}{ Other disease } & Yes & 77 & 18.4 \\
\hline & No & 341 & 81.6 \\
\hline \multirow[t]{2}{*}{ Medical condition } & Acute illness & 340 & 81.3 \\
\hline & Chronic illness & 78 & 18.7 \\
\hline \multirow[t]{2}{*}{ Family support } & Yes & 389 & 93.0 \\
\hline & No & 29 & 7.0 \\
\hline \multirow[t]{2}{*}{ Type of room of admission } & Common room & 386 & 92.3 \\
\hline & Private room & 16 & 7.7 \\
\hline \multirow[t]{4}{*}{ Feeling about hospital cost } & High & 158 & 46.5 \\
\hline & Medium & 178 & 52.4 \\
\hline & Low & 2 & 0.6 \\
\hline & Uncertain & 2 & 0.6 \\
\hline
\end{tabular}

Table 2: Patient and admission-related characteristics of the participants in public hospitals of Benishangul Gumuze ( $\mathrm{n}=418)$. 
Citation: Kewi SY, Tesema AA, Negussie BB (2018) Patient's Perception towards Quality of Nursing Care in Inpatient Department at Public Hospitals of Benishangul Gumuz Regional State, North West Ethiopia. J Nurs Care 7: 467. doi:10.4172/2167-1168.1000467

Page 7 of 10

Concerning on the caring environment, 308 (73.7\%), 329 (78.8), 313 (74.9\%), and 239 (57.2\%) of respondents had good perception on ventilation of the ward, lighting condition of the ward, safety and security in the ward and information displayed at the entrance respectively. On the last dimension, $247(59.1 \%)$ and $273(65.3 \%)$ of them had good perception on nurses' competency and enough knowledgeable to answer their questions.
From the six dimensions, the overall patients' perception was mostly related with interpersonal dimension where the correlation coefficient value $r=0.751$ and it was lesser related with comfort related dimension of nursing care where the correlation coefficient value $r=0.234$. Combined score of patient's perception in each of the six dimensions is summarized in Tables 3 and 4.

\begin{tabular}{|l|l|l|l|l|}
\hline S. No & Aspect & Good perception & Poor perception & Total \\
\hline & & No $(\%)$ & No $(\%)$ & $\%$ \\
\hline 1 & Interpersonal care & $202(48.3)$ & $216(51.7)$ & 100 \\
\hline 2 & Efficiency & $161(38.5)$ & $257(61.5)$ & 100 \\
\hline 3 & Comfort & $206(49.3)$ & $212(50.7)$ & 100 \\
\hline 4 & Information & $105(25.1)$ & $313(74.9)$ & 100 \\
\hline 5 & Environment & $172(41.1)$ & $246(58.9)$ & 100 \\
\hline 6 & Competency & $180(43.1)$ & $238(56.9)$ & 100 \\
\hline Overall & & $206(49.3)$ & $212(50.7)$ & 100 \\
\hline
\end{tabular}

Table 3: Patients' perception on nursing care at public hospitals of Benishangul Gumuze ( $n=418)$.

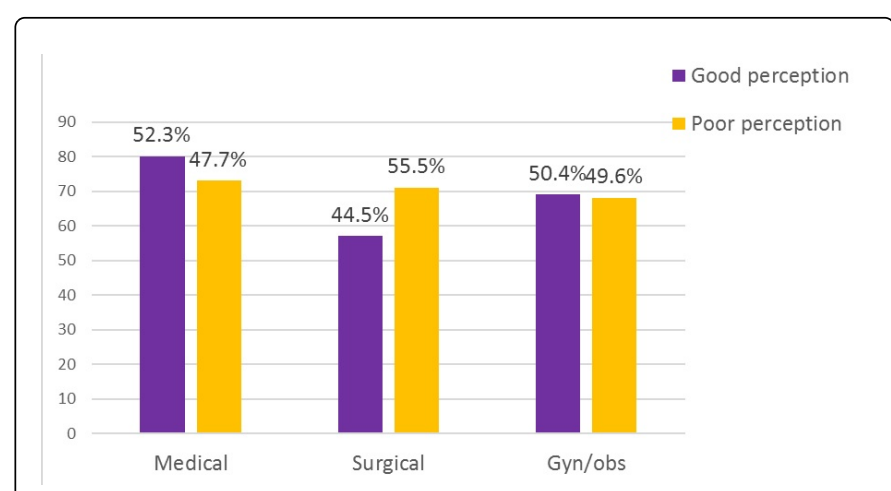

Figure 3: Type of ward VS patients' perception of quality of nursing care in public hospitals of Benishangul Gumuze $(n=418)$.

\section{Logistic regression analysis on patients' perception of quality of nursing care}

The results from binary logistic analyses showed that there were relationship between sex, educational status, history of previous admission, income, number of days (nights) stayed in hospital, family support and type of admission room with patients' overall perception with nursing care quality. In multiple logistic regression analysis, educational status, length of hospital stay, family support/companion possession, type of admission room and hospital setting were found to be statistically significant predictors of patients' perception.

Accordingly, patients who were unable to read and write were 21 times more likely to have good perception towards nursing care quality than those who had College Diploma and above [AOR=21.026 and $95 \%$ CI $(7.433,59.479)]$. Regarding number of days stayed in hospital, those patients who stayed for $\leq 7$ nights were 2.39 times more likely to have good perception compared to those stayed for $\geq 8$ nights [AOR=2.386 and 95\% CI (1.209, 4.709)].

In addition, the study result showed that patients who had family support were 3.5 times more likely to have good perception towards nursing care quality compared to those who had no support/ companion possession [AOR=3.531 and 95\% CI $(1.475,8.453)]$. Patients who were admitted to private room were 3.68 times more likely to have good perception towards nursing care quality compared to those admitted in common room [ $(\mathrm{AOR}=3.676$ and $95 \% \mathrm{CI}(1.534$, 8.811)]. This study also showed that patients admitted in Pawe Hospital were 1.7 time more likely to have good perception on nursing care quality than those who were admitted in Assosa Hospital [AOR $=1.724$ and $95 \% \mathrm{CI}(1.127,2.636)]$.

\section{Discussion}

This study revealed that the overall proportion of patients who had good perception on the quality of nursing care was $49.3 \%$. This finding was consistent with the study done in north Ethiopia 50.3\% [25]. But this percentage was lower compared to other studies conducted in Sri Lankan hospital 70\%, Nepal 63.6\% and Kenya 67.8\% [4,26,27]. This difference might be related with variation in socio-demographic characteristic of study participants, the level of hospitals studied, nurse staffing and differences in doctor-patient relationship or nurses' participation in decision making process.

This study revealed that $48.3 \%$ of respondents had good perception on interpersonal nursing care related dimension which was lower compared to other studies conducted in Sri Lanka 63.07\% and Nepal $65[4,28]$. This discrepancy might be because of nurses prioritized the completion of job related tasks rather than spending time to talk, work overload or due to lack of the concept of patient centered care. From the second dimension of efficiency related nursing care, this study revealed that $39.2 \%$ of participants perceived good as nurses gave them treatment/medication without any delay. This finding was lower than 
Citation: Kewi SY, Tesema AA, Negussie BB (2018) Patient's Perception towards Quality of Nursing Care in Inpatient Department at Public Hospitals of Benishangul Gumuz Regional State, North West Ethiopia. J Nurs Care 7: 467. doi:10.4172/2167-1168.1000467

Page 8 of 10

study conducted in Jordan $66 \%$. Also in our study $40.2 \%$ of patients perceived good as nurses maintain good coordination with other staff which was lower than study done in Jordan $66 \%$ [19]. This could have explained that staff members might not be sensitized to the importance of on-time medication administration, lack of understanding of the specific information or poor communication within the staff.

Regarding on information, our result showed that $26.6 \%$ and $38.8 \%$ of them had good perception as they have got enough information regarding their illness and investigation from nurses respectively, which was lower than study conducted in North Ethiopia $70.6 \%$ and $91.4 \%$ respectively [25]. This might be because of either the nurses' reluctance to exhibit these important qualities of providing care or their ignorance of the skills altogether.

\begin{tabular}{|c|c|c|c|c|c|c|}
\hline \multirow[t]{2}{*}{ Variables } & \multirow[t]{2}{*}{ Label/category } & \multicolumn{2}{|l|}{ Patient perception } & COR $(95 \% \mathrm{Cl})$ & AOR $(95 \% \mathrm{Cl})$ & \multirow[t]{2}{*}{ p-value } \\
\hline & & Good perception (N, \%) & Poor perception (N, \%) & & & \\
\hline \multirow[t]{5}{*}{ Educational status } & Unable to read and write & $93(45.1)$ & $52(24.5)$ & $\begin{array}{l}13.950 \\
37.578)\end{array}$ & $\begin{array}{l}21.026 \\
59.479)\end{array} \quad(7.433$, & 0.001 \\
\hline & Able to read and write & $22(10.7)$ & $29(13.7)$ & $5.917(2.003,17.485)$ & $8.897(2.852,27.756)$ & 0.001 \\
\hline & Primary school & $51(24.8)$ & $50(23.6)$ & $7.956(2.899,21.831)$ & $\begin{array}{l}10.740 \\
30.748)\end{array}$ & 0.001 \\
\hline & Secondary School & $35(17.0)$ & $42(19.8)$ & $6.500(2.313,18.270)$ & $8.228(2.819,24.017)$ & 0.001 \\
\hline & College and above & $5(2.4)$ & $39(18.4)$ & 1 & 1 & \\
\hline \multirow[t]{2}{*}{ Length of hospital stay } & $\leq 7$ days & $190(92.2)$ & $181(85.4)$ & $0.492(.260, .292)$ & $2.386(1.209,4.709)$ & 0.012 \\
\hline & $\geq 8$ days & $16(7.8)$ & $31(14.6)$ & 1 & 1 & \\
\hline \multirow[t]{2}{*}{ Family support } & Yes & $198(96.1)$ & $191(90.1)$ & $2.721(1.177,6.292))$ & $3.531(1.475,8.453)$ & 0.005 \\
\hline & No & $8(3.9)$ & $21(9.9)$ & 1 & 1 & \\
\hline \multirow{2}{*}{$\begin{array}{l}\text { Type of admission } \\
\text { room }\end{array}$} & Common room & $184(89.3)$ & $202(95.3)$ & 1 & 1 & \\
\hline & Private room & $22(10.7)$ & $10(4.7)$ & $.492(.260,0.929)$ & $3.676(1.534,8.811)$ & 0.004 \\
\hline \multirow[t]{2}{*}{ Hospital Setting } & Pawe Hospital & $121(55.3)$ & $98(44.7)$ & $1.656(1.124,2.439)$ & $1.724(1.127,2.636)$ & 0.012 \\
\hline & Assosa Hospital & $85(42.7)$ & $114(57.3)$ & 1 & 1 & \\
\hline
\end{tabular}

Table 4: Bivariate and multivariate logistic regression analysis on patients' overall perception of nursing care quality in public hospitals of Benishangul Gumuze ( $\mathrm{n}=418)$.

The study done in Sri Lanka $69.3 \%$, North Ethiopia $94.7 \%$ and Nepal $66.4 \%$ of respondents had good perception on the nursing care environment $[4,25-29]$. But the current study showed only $41.1 \%$ of patients had good perception on the nursing care environment. This difference may be due to lack of resources or inadequate equipment in our study setting. Concerning nurses' competency, only $43.1 \%$ of participants had good perception as nurses who gave care for them were competent, which was lower than study conducted in Jordan $62 \%$, Northwest Ethiopia $80.2 \%$ and China $84 \%[4,19,30]$. This might be due to difference in nurses to patient ratio, the level of hospitals, and advancement of technologies which were used to provide quality nursing care.

The findings of this study showed that there was no relationship between socio demographic variables including gender, age, marital status, ethnicity, and religion with patient's overall perception. This finding was similar with study conducted in Nepal and China $[26,30]$. In various studies conducted on the subject; it was found that the patients' gender $[9,15]$ and age $[9,15,31]$ had significant association with patients' perception on nursing care. This can be due to the difference in socioeconomic difference and level of understanding on quality of services.

The study showed that educational level was significantly associated with patient perception. This finding was in line with the study done in Turkey and Addis Ababa [9,32]. This could be explained by people who are highly educated might expect a higher standard of care than lower education status. In contrary, study done in Gamo Gofa and Mekelle showed that respondents attended college and University were more likely to be satisfied with nursing care service provided than illiterate once [31,32].

Patients' number of night spent in the ward had also an association with patients' perception. In this study those patients who spent $\leq 7$ nights were 2.39 times more likely to have good perception than who spent $\geq 8$ nights. It may because those who spent $\geq 8$ nights might have a higher demand and they might have some other hospital acquired infection as they spent more time in the hospital. This finding was in agreement with study done in Turkey, Gamo Gofa and Black Lion $[9,31,32]$. 
In our study patients who had family support were 3.5 times more likely to have good perception towards nursing care quality compared to those who had no support/companion possession. This might be due to the possibility of decrease in expectations of nursing care because of companions met the patient's needs. In contrast, studies done in Turkey [1] revealed that there is no association between family support and patient perception on nursing care. This can be due to the difference level of caring in the hospital, availability of quality control and assurance at the hospital and the staffing.

Concerning the type of admission room, those admitted to private room were 3.68 times more likely to have good perception towards nursing care quality compared to those admitted in common rooms. It is in agreement with study done in Dessie Referral Hospital [15]. This might be related with the privacy and nurses perform their nursing duties in a careful and meticulous manner in the private room and also patients admitted at private room can get conducive environment for care and information about their disease and prognosis. Patients who were admitted to Pawe Hospital had good perception towards nursing care quality than those who cared in Assosa Hospital. This might be related to the difference in physical environment or the level of understanding of patients and difference of quality services between the two hospitals.

\section{Conclusion}

In conclusion, the level of overall adult patients' perception about the quality of nursing care in the hospitals was low. Number of nurses available for their care, ventilation of the ward, safety and security in the ward and lighting condition of the ward were the four top items that patients were more satisfied. In contrary, the amount and type of information nurses gave to patients about their illness and investigation, the way nurses took immediate care for their request and cleanliness of the bed were the least satisfied items. These were the common problems for hospitals under study which requires urgent attention to enhance patients' perception at the same time to insure quality of nursing care. Patients' level of education, duration of hospitalization, family support/companion possession, type of admission rooms and type of hospital were identified as independent factors influencing the patients' perception among the admitted patients.

\section{Recommendations}

The regional health bureau is recommended to design and launch intervention programs to improve the information provision and communication skills and the skills of making clients feel well of the nursing staff at the study hospitals. Regularly evaluate patients' perception to ensure the sustainability of quality of nursing care services. Hospital administrators also should have more efforts to ensure the nursing care environmental cleanliness by improving availability of necessary materials and supplies. The hospital should strengthen operational standards of nursing care practice to the staffs. Organize nursing education program and skill training workshops for the nurse's. Nursing staff should focus on patient centered care to reduce patient's length of hospital stay. The staffs should also consider consistent care for private and common rooms including patient's privacy and confidentiality during care. Further study is needed to understand the overall patients feeling using qualitative study and also the care providers' perceptions should be examined.

\section{Acknowledgment}

We would like to thank Pawe Health Science College for sponsoring this study and Pawe general hospital and Assosa general hospital for their cooperation in giving valuable data source. Our deepest thanks also extended to Jimma University, particularly instructors at the school of nursing and midwifery who supported us either directly or indirectly by giving a constructive comments and guidance. Last but not least, we would not wrap up without thanking our data collectors and supervisors for their support and encouragement throughout this work and patients who participated in this study for their willingness to share their experiences.

\section{Conflict of Interest}

All authors declared that there is no conflict of interest. Funder of this study was acknowledged and they have no contribution in publication process.

\section{References}

1. Ali M, Kol E, Arıkan F, Emine I (2018) A quality indicator for the evaluation of nursing care: determination of patient satisfaction and related factors at a university hospital in the Mediterranean Region in Turkey. Collegian 25: 51-56.

2. Lang NM (1983) Assessment and assurance of the quality of nursing care. SAGE 6: 211-231.

3. Donabedian A, Wheeler JR, Wyszewianski L (1982) Quality, cost and health: An integrative model. Med Care 20: 975-992.

4. Muraleeeswaran R, Thenuka M (2016) Patient's perceptions regarding quality nursing care in a Sri Lankan hospital. IJIR 5: 1553-1556.

5. Ervin NE (2016) Does patient satisfaction contribute to nursing care quality? J Nurs Adm 36: 126-130.

6. Desta H, Berhe T, Hintsa S (2018) Assessment of patients's satisfaction and associated factors among outpatients received mental health services at public hospitals of Mekelle Town, northern Ethiopia. Int J Ment Health Syst 12: 38 .

7. Gupta BS, Shrestha S, Thulung BK (2014) Patient's perception towards quality nursing care. J Nepal Health Res Counc 12: 83-87.

8. Senarath U, Gunawardena NS (2011) Development of an instrument to measure patient perception of the quality of nursing care and elated hospital services at the National Hospital of Sri Lanka. Asian Nurs Res 5: 71-80.

9. Dikmen Y, Yllmaz D (2016) Patient's perceptions of nursing care-A descriptive study from Turkey. Ann Nurs Pract 3: 1048.

10. Rajeswari $\mathrm{T}$ (2018) A study to assess patient's satisfaction with quality of nursing care.11: 15-71.

11. Ferlie EB, Shortell SM (2011) Improving the quality of health care in the United Kingdom and the United States: A framework for change. Milbank Q 79: 281-315.

12. Codier E, Kooker, BM, Shoultz J (2008) Measuring the emotional intelligence of clinical staff nurses: an approach for improving the clinical care environment. Nurs Adm Q 32: 8-14.

13. Negash AK, Negussie WD (2014) Patients' satisfaction and associated factors with nursing care services in selected hospitals, Northwest Ethiopia. Am J Nurs Sci 3: 34-42.

14. Suresh K, Sharma KP (2013) Patient Satisfaction with nursing care in public and private hospitals. Nurs Midwifery Res J. 9.

15. Eyasu KH, Adane AA, Amdie FZ, Getahun TB, Biwota MA (2014) Adult patients' satisfaction with inpatient nursing care and associated factors in an Ethiopian Referral Hospital, Northeast Ethiopia. 16: 7.

16. DzomekuVM, Etilayoo A, Perekuu TR (2013) In-patient satisfaction with nursing care: a case study at Kwame Nkrumah University of science and technology hospital. Int J Res Med Heal Sci 2. 
Citation: Kewi SY, Tesema AA, Negussie BB (2018) Patient's Perception towards Quality of Nursing Care in Inpatient Department at Public Hospitals of Benishangul Gumuz Regional State, North West Ethiopia. J Nurs Care 7: 467. doi:10.4172/2167-1168.1000467

Page 10 of 10

17. Akhtari-Zavare M, Abdullah MY, Hassan STS, Said SB KM (2010) Patient satisfaction: Evaluating nursing care for patients hospitalized with cancer in tehran teaching hospitals, Iran. Glob J Health Sci 2.

18. Jijia KM, Su-mei H, Ziying S (2015) A study of the changing health care environment so as to meet patient's needs and expectations. 2: 541-544.

19. Al-hussami M, Al-momani M, Hammad S, Maharmeh M, Darawad M (2017) Patients' perception of the quality of nursing care and related hospital services. 1: 1-6.

20. Ella R (2012) Factors influencing patients perception of nurses respect for their dignity in a public hospital in calabar, Nigeria. IJHSSE 8: 72-81.

21. Li M, Lowrie DB, Huang C, Lu X, Zhu Y, Wu X, et al. (2015) Use of the servqual scale. Asian Pac J Trop Biomed [Internet]. Elsevier 5: 497-504.

22. FMOH (2015) Ethiopian national health care quality strategy, 2016-2020. Transforming the quality of health care in Ethiopia.8: 88.

23. Wandera M, Onyango RKR (2014) Determinants of clients' satisfaction with healthcare services at Pumwani Maternity Hospital in NairobiKenya. Int J Soc Behav Sci 2: 011-017.

24. Hadgu (2015) Quality of nursing care among in-patient of medicalsurgical ward in axum St. Marry Hospital, Tigray, Ethiopia, 2015. Enz Eng 4: 2.

25. Teferi M (2017) Assessment of adult patients' perception of nursing care and its contributing factors at ayder referral hospital, Mekelle Ethiopia, 2016. JPAM 14: 1-8.
26. Twayana S, Adhikari RH (2015) Patient's perception regarding nursing care at inpatient department of hospitals in bhaktapur district. IJSRP 5: 5-7.

27. Ndambuki J (2013) The level of patient's satisfaction and perception on quality of nursing services in the Renal unit, Kenyatta National Hospital Nairobi, Kenya. OJN 3: 186-194.

28. World Health Organization (2006) A process for making strategic choices in health system. Qual care.

29. Negash AK, Negussie WD, Demissie AF (2014) Patient's satisfaction and associated factors with nursing care services in selected hospitals, Northwest Ethiopia. Obstet Gynecol Int 3: 34-42.

30. Zhao SH, Akkadechanunt $\mathrm{T}$ (2011) Patient's perceptions of quality nursing care in a Chinese hospital. International Journal of Nursing and Midwifery 3: 145-149.

31. Mende, Taye A, Katene S, Abera F, Ochare O (2017) Determinants of patient satisfaction towards inpatient nursing services and its associated factors in, Gamo Gofa Zone, SNNPR, Ethiopia, April 2017. Clinical \& Medical Case Reports 7: 00205.

32. Molla M, Berhe A, Shumye A, Adama Y (2014) Assessment of adult patients' satisfaction and associated factors with nursing care in Black Lion Hospital, Ethopia: Instutional based cross sectional study. Int J Nurs Midwifery 6: 49-57.

33. 